\title{
EFFECT OF FLY ASH, HUMAN HAIR FIBER AND PHOSPHOGYPSUM ON PROPERTIES OF EXPANSIVE SOILS
}

\author{
Mir Tariq Khurshid, Irfan Yousuf Wani \\ PG Student M. Tech Soil Mechanics And Foundation Engineering \\ Sri Sai college of Engineering and Technology, \\ IKGPTU Pathankot Punjab India \\ Er.Neeraj Sharma \\ Asst. Prof. Civil Engineering Department \\ Sri Sai college of Engineering and Technology, \\ IKGPTU Pathankot Punjab India.
}

\begin{abstract}
Nearly 51.8 million hectares of land area in India are covered with Expansive soil. The property of these expansive soils is that they are very hard when in dry state, but they lose all of their strength when in wet state. In context to this property of expansive soils, these soils pose numerous problems worldwide that serve as challenge to overcome for the Geotechnical engineers. One of the most important aspects for construction purposes is soil stabilization, which is used widely in foundation and road pavement constructions; this is because such a stabilization regime improves engineering properties of the soil, such as volume stability, strength and durability. In this process, removal or replacing of the problematic soil is done; replacement is done by a better quality material, or the soil is treated with an additive. In the present study, addition of fly ash, Phosphogypsum and Human Hair Fiber in various proportions results in increase in plasticity of the expansive soil, and increase in workability by changing its grain size and colloidal reaction. Analysis of the formerly found result exposes the potential of fly ash, PG and HHF as additives could be used for improving the engineering properties of expansive soils.
\end{abstract}

Keywords - Expansive Soil, Fly Ash, Human Hair Fibre, Phosphogypsum Liquid limit, Unconfined compressive strength, CBR

\section{INTRODUCTION}

SOIL formation, or pedogenesis, is the combined effect of physical, chemical, biological and anthropogenic processes working on soil parent material. Soil is said to be formed when organic matter has accumulated and colloids are washed downwards, leaving deposits of clay, humus, iron oxide, carbonate, and gypsum, producing a distinct layer called soil.
Soil can be defined as the loose surface material which is overlying over the solid rocks. Therefore this thing is justified that the soil that is one of the most ancient construction material will still be among the most widely used material due to its low cost, wide spread nature and its easy availability on this planet earth. The formation of the soil is generally due to the decomposition of rocks and with the help of transportation and weathering of products of decomposition. The result may be inorganic sediments of soil, or may be organic residue, plant roots, or various other unwanted material of the industries in the soil.

\section{MATERIALS}

\section{A. Fly Ash}

Fly ash, which is extracted during the combustion of coal in fired power plants is a waste material. These have close resemblance with the volcanic ashes, which were used as hydraulic cements in ancient ages. These volcanic ashes were considered as one of the best pozzolanas used till now in the world.

Safe disposal and management of FA are the two major issues concerned with the production of FA. Generally the wastes which are generated from the industries possess very complex characteristics and are very hazardous, therefore it is necessary to safely and effectively dispose these wastes, so that it will not disturb the Ecological System and will not cause any misadventure to natural and human life. There should be provision of pre-treatment of these industrial wastes before its disposal and storage; otherwise it will cause environmental pollution. Generally the fly ashes are micro sized particles which essentially consist of alumina, silica and iron. These particles are generally spherical in size, which makes them easy to flow and blend, to make a suitable mixture. 


\section{B. Phosphogypsum}

Phosphogypsum refers to the calcium sulfate hydrate formed as a by-product of the production of fertilizer from phosphate rock. It is mainly composed of gypsum (CaSO). It is largely calcium sulfate and has given the name phosphogypsum. Phosphogypsum causes many environmental pollution problems. Phosphogypsum contains impurities of free phosphoric acid, phosphates, fluorides and organic matter. Although the chemical composition of PG is the same with the chemical composition of natural gypsum, its use as natural gypsum is limited due to the some impurities. For apart phosphogypsum is widely material used in construction industry. PG has been used as set controller in the manufacture of Portland cement, as a raw material for clinker, as a secondary binder with lime and cement, in the production of artificial aggregates, and in road stabilization. In this study, PG finer than 75 micron, Indian Standard sieve, was used as an admixture

\section{Human Hair Fiber (HHF)}

Human hair is considered as a waste material in most parts of the world and is a common constituent found in municipal waste streams which cause enormous environmental problems from its degradation. In rural areas or areas with low population density, the hair is thrown away in nature where it slowly decomposes over several years, eventually returning the constituent elements, namely, carbon, nitrogen, sulfur, and so forth, to their respective natural cycles. In urban areas or areas with high population density, it often accumulates in large amounts in the solid waste streams and chokes the drainage systems, posing a multifaceted problem. Human Hair Fiber (HHF) is a non degradable matter available in abundance and at a very cheap cost. Human hair fiber is good in tension; hence it can be used as a fiber reinforcing material. Also the high tensile strength, unique chemical composition, thermal insulation etc. For stabilization of expansive soils this fiber can make strong bonds and work as reinforcement agent, which in result it increases shear strength and reduces the chances of swelling characteristic. It will also increase bearing capacity.

\section{EXPERIMENT AND RESULT}

\section{The 3.1 Consistency Limit Test}

Consistency limit defines the state of soil in which it exists. This test includes the determination of liquid limit, plastic limit and plasticity index of clay. It has been found that there is decrease in the liquid limit and plasticity index till optimum mix (73.5:5:1.5:20) after that increases. There is decrease in the value of liquid limit from $56 \%$ to $44.24 \%$ and from $29 \%$ to $10.1 \%$ in case of plasticity index and there is increase in the case of plastic limit from $27 \%$ to $34.14 \%$.

The increase in liquid limit after optimum mix is due to the flocculation in the soil particles which increases the water holding capacity within the flocculated structure. The reduction in plasticity index is due to agglomeration, presence of more amount of cementitous material reduces plasticity index of soil. The reduction in plasticity index is due to significant decrease in the thickness of double layer of the clay particles. This is because of cation exchange reaction, which causes an increase in the attraction force leading to the flocculation of clay particles.
On the basis of the consistency limit test, the classification and compressibility behavior of the soil can be investigated, due to which it is found that soil is highly compressible or low compressible. The compressibility behavior can be checked with the help of liquid limit and plasticity index value in the Plasticity chart.

Table 3.1 Variation of LL, PL and PI for various proportions of Soil, PG and HHF with constant value of FA.

\begin{tabular}{|c|c|c|c|}
\hline $\begin{array}{c}\text { SOIL : PG : } \\
\text { HHF :FA }\end{array}$ & LL (\%) & PL (\%) & PI (\%) \\
\hline $100: 00: 00: 00$ & 56 & 27 & 29 \\
\hline $78.5: 1: 0.5: 20$ & 51.31 & 31.4 & 19.91 \\
\hline $76.5: 3: 0.5: 20$ & 50.27 & 32.01 & 18.26 \\
\hline $74.5: 5: 0.520$ & 49.88 & 33.07 & 16.81 \\
\hline $72.5: 7: 0.5: 20$ & 48.14 & 33.8 & 14.34 \\
\hline $78: 1: 1: 20$ & 49.79 & 31.87 & 17.92 \\
\hline $76: 3: 1: 20$ & 48.56 & 32.90 & 16.47 \\
\hline $74: 5: 1: 20$ & 46.91 & 33.02 & 13.89 \\
\hline $72: 7: 1: 20$ & 45.63 & 33.93 & 11.7 \\
\hline $77.5: 1: 1.5: 20$ & 49.13 & 32.24 & 16.89 \\
\hline $75.5: 3: 1.5: 20$ & 47.78 & 33.6 & 14.18 \\
\hline $\mathbf{7 3 . 5}: \mathbf{5}: \mathbf{1 . 5}: \mathbf{2 0}$ & $\mathbf{4 4 . 2 4}$ & $\mathbf{3 4 . 1 4}$ & $\mathbf{1 0 . 1}$ \\
\hline $71.5: 7: 1.5: 20$ & 45.07 & 32.89 & 12.18 \\
\hline $77: 1: 2: 20$ & 48.21 & 31.6 & 16.18 \\
\hline $75: 3: 2: 20$ & 48 & 32.03 & 15.97 \\
\hline $73: 5: 2: 20$ & 49.43 & 30.76 & 18.67 \\
\hline $71: 7: 2: 20$ & 50.87 & 29.32 & 21.55 \\
\hline
\end{tabular}

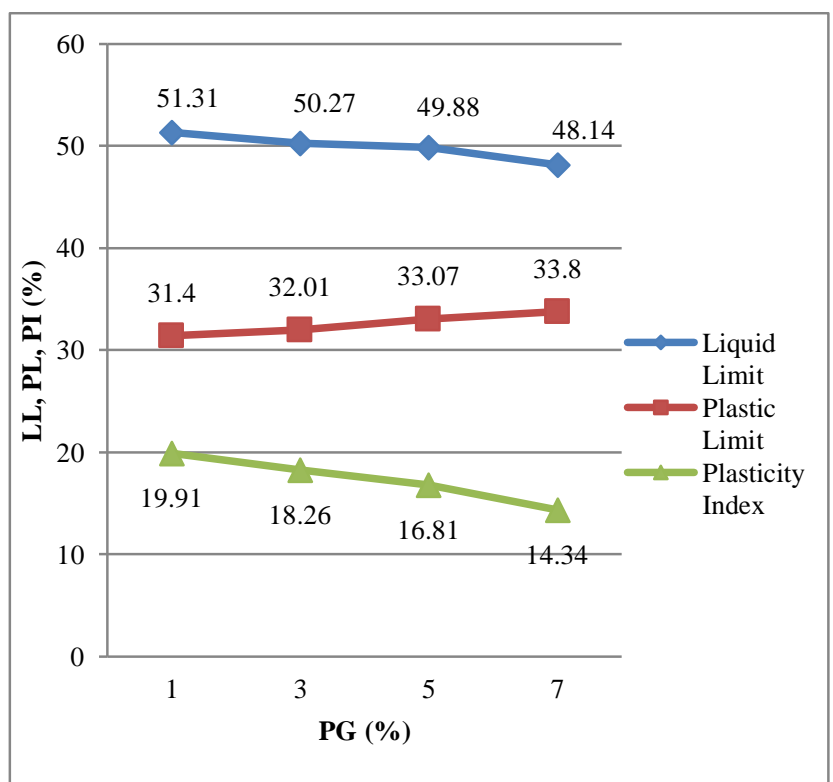

Fig. 3.1 Consistency limits of mix having 20\% FA and 0.5 HHF with various proportion of PG and Soil

Figure 3.1 shows the consistency limits i.e. liquid limit, plastic limit and plasticity index of the Soil mixed with $20 \%$ of FA and $0.5 \mathrm{HHF}$ with $1 \%, 3 \%, 5 \%, 7 \%$ of PG. It shows that at $20 \%$ of FA and 0.5 HHF the liquid limit of the mix decreases as the content of PG increases up to a certain limit. In case of plastic 
limit the effect is opposite to liquid limit, as plastic limit increases with increase in PG. The plasticity index curve shows same results as liquid limit.

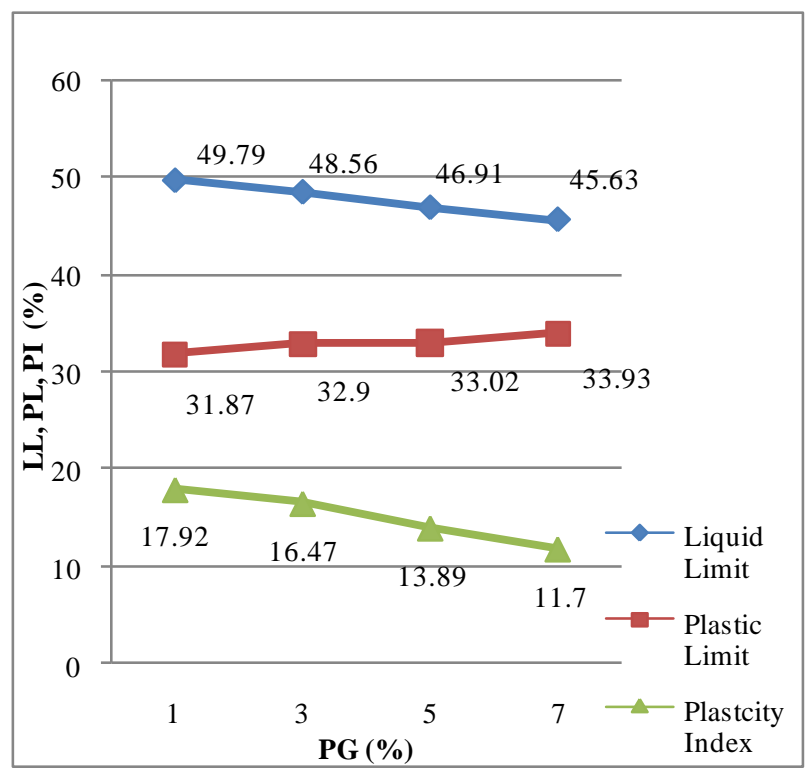

Fig. 3.2 Consistency limits of mix having 20\% FA and

1(\%) HHF with various proportion of PG and Soil

Figure 3.2 shows the consistency limits of the Soil mixed with $20 \%$ FA and $1 \%$ of $\mathrm{HHF}$ with $1 \%, 3 \%, 5 \%$, and $7 \%$ of PG. It shows that at $20 \%$ of FA and $1 \%$ of $\mathrm{HHF}$, the liquid limit of the mix decreases as the content of PG increases. In case of plastic limit there is increase in the value with increase in PG content. The plasticity index curve shows opposite results of liquid limit.

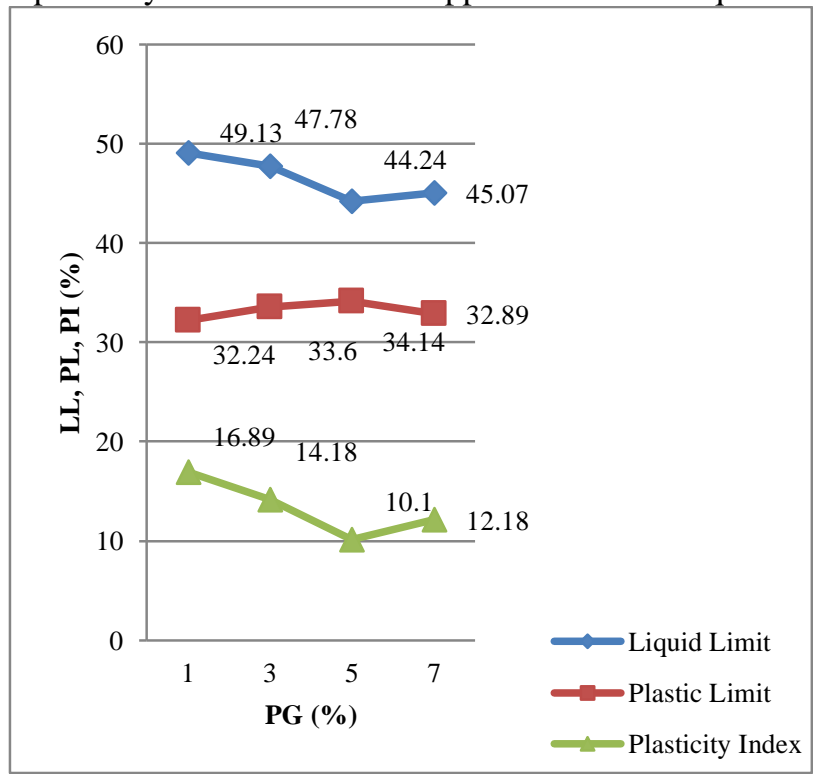

Fig.3.3 Consistency limits of mix having 20\% FA And 1.5 (\%) with various proportion of PG and Soil

Figure 3.3 shows the consistency limits of the Soil mixed with $20 \%$ FA and $1.5 \%$ of HHF with $1 \%, 3 \%, 5 \%$, and $7 \%$ of PG. It shows that at $20 \%$ of FA and $1.5 \%$ of HHF, the liquid limit of the mix decreases as the content of PG increases up to $5 \%$ to limit then increase. In case of plastic limit there is increase in the value with increase in PG content at $5 \%$ after that it decreases. The plasticity index curve shows opposite results of

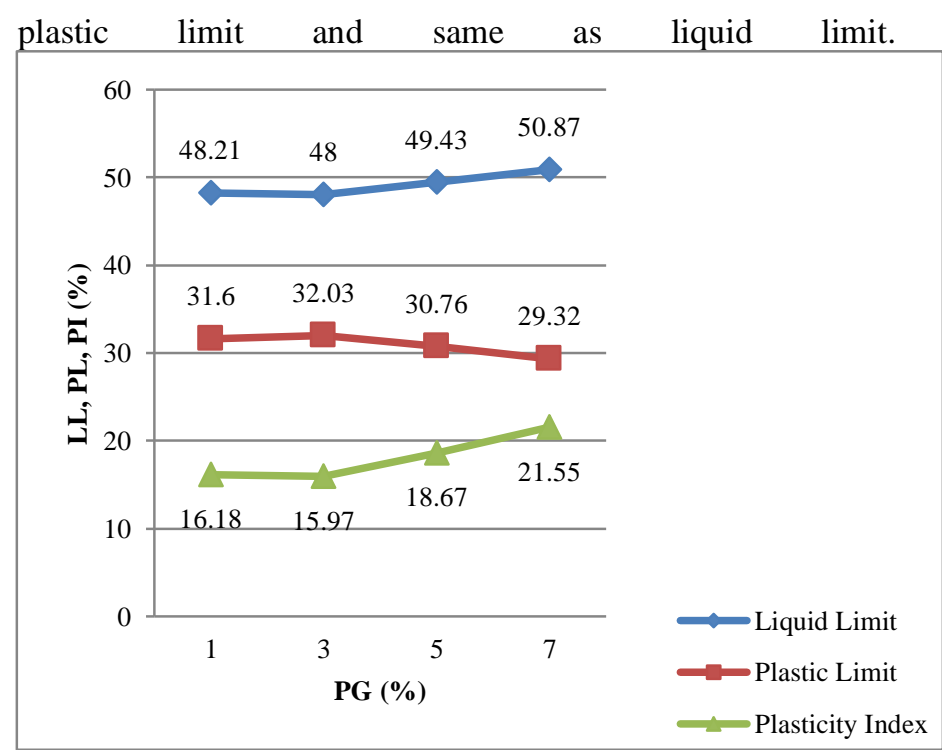

Fig.3.4 Consistency limits of mix having 20\% FA and 2

(\%) HHF with various proportion of PG and Soil Figure 3.4 shows the consistency limits of the clay mixed with $20 \%$ FA and $2 \%$ of $\mathrm{HHF}$ with $1 \%, 3 \%, 5 \%$, and $7 \%$ of PG. It shows that at $20 \%$ of FA and $2 \%$ of HHF, the liquid limit of the mix decreases as the content of PG increases up to 5\% to limit then increase. In case of plastic limit there is increase in the value with increase in PG content at $5 \%$ after that it decreases. The plasticity index curve shows same results of liquid limit and opposite of plastic limit.

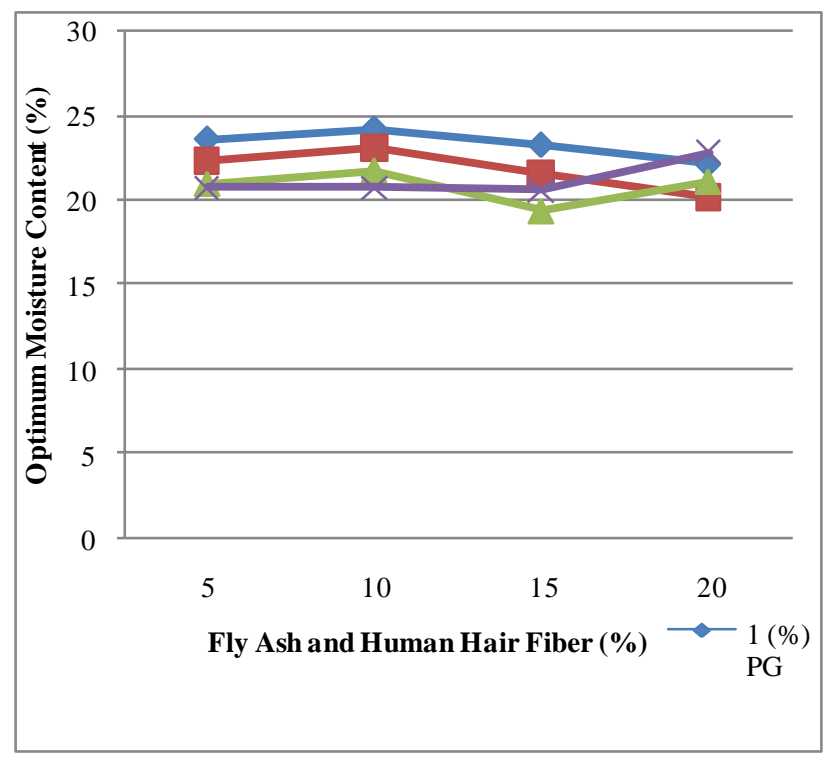

Fig. 3.5 OMC v/s Percentage of PG with 1\%, 3\%, 5\%, 7\% of HHF and FA with different proportions of Soil.

Figure 3.5 shows the optimum moisture content of $20 \%$ FA at different proportions of $\mathrm{PG}$ and $\mathrm{HHF}$ i.e. $1 \%, 3 \%, 5 \%, 7 \%$ and $0.1 \%, 1 \%, 1.5 \% 2 \%$ respectively. As per the graph of $1 \%$ and $2 \%$ PG the OMC value decreases. In the 5\% and $7 \%$ graph, value of OMC also decreases up to a certain limits and then after increase. In the case of $5 \%$ the optimum value is 73.5:5:1.5:20 and in case of $7 \%$ the optimum value is $75: 3: 2: 20$. 


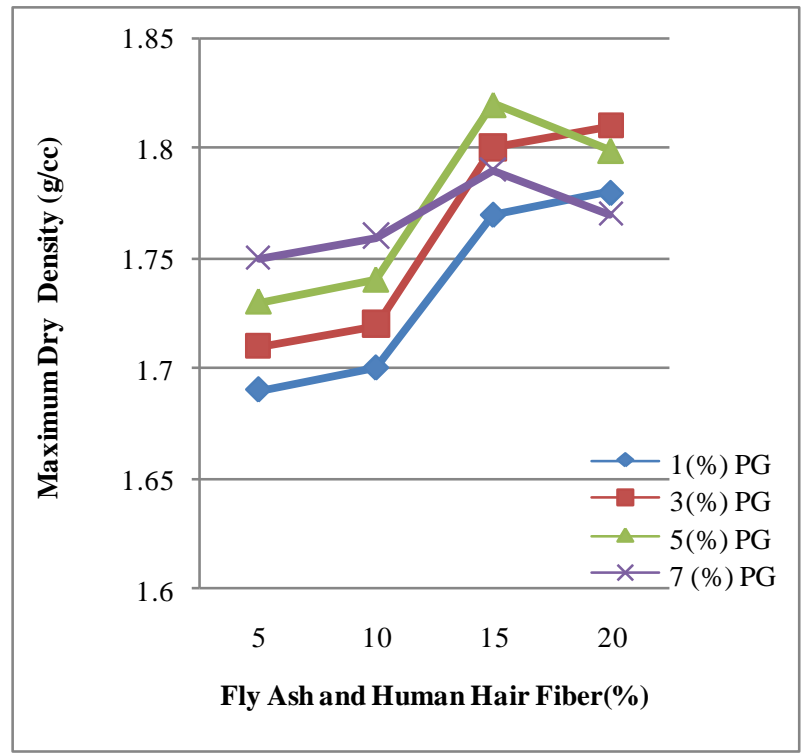

Fig. 3.6 MDD v/s Percentage of PG with 1\%, 3\%, 5\%, 7\% of HHF and FA with different proportions of Soil

Figure 3.6 shows the maximum dry density of $1 \%, 3 \%, 5 \%$ and $7 \%$ PG at different proportions of $\mathrm{HHB}$ i.e. $0.5 \%, 1.0 \%, 1.5$ $\%$ and $2 \%$ and $20 \%$ of FA. In graph $1 \%$ and $3 \%$ the Maximum Dry density increases with the increase in proportions. In $5 \%$ and $7 \%$ graphs the MDD increases up to a certain limit and then decreases so the optimum mix is $73.5: 5: 1.5: 20$ and $75: 3: 2: 10$ respectively.

\section{CONCLUSION}

[1] The optimum mix is found to be $73.5 \%$ soil, $20 \% \mathrm{FA}, 5 \% \mathrm{PG}$ and $1.5 \% \mathrm{HHF}$ on the basis of consistency limit test and compaction test.

[2] The MDD increases from 1.63 to 1.82 and OMC decreases from 28.34 to 19.34 with increase in percentage of FA, PG \& HHF into the soil.

[3] Adding Hair in between layers of soil strengthens its interlocking ability among soil particles, thus, providing a strong bond to it.

[4] This study shows that soil stabilization is beneficial for stabilizing the weak soils. Solid wastes from industries should be encouraged to be used as stabilizers instead of expensive chemical stabilizers.

[5] The fly ash particles served as nucleation sites for the growth of hydration products with their formation, initiating from the surface.

[6] Based on the tests results and investigation conducted on soil sample the following conclusions were given, it may be concluded that human hair can be used as a natural reinforcing agent for stabilization of soft clayey soils. Human hair fiber has good strength properties, low cost and high toughness to biodegradability. It is also useful for the stability of slopes.

\section{REFERENCE}

[1] Atul Krishna Takur, Haris Sheikh, (2018), "Soil Stabilization Using Human Hair Fiber", International journal for emerging research and development, Vol.1, Issue 2, pp.89-94.
[2] Anoop Sharma, Dr. B.S. Walia, (2017), "Effect of Phosphogypsum and Fly ash on the CBR and UCS of clayey soil" International Journal of Engineering Trends and Technology (IJETT) - Volume 50 Number 5 August 2017.

[3] [Ujwal Mishra, (2017), "Human Hair Fiber: A Discrete fiber to improve soil sub grade strength: A Review", International journal of innovative Research and advanced studies, Vol.4, Issue 3, pp.339-343.

[4] K Shankar Narayanan, S Mary, (2017), "Stabilization of Clay with Human Hair Fiber", International journal of civil engineering and technology, Vol.8, Issue 4, pp.662-667.

[5] Malik, A., and Thapliyal, A. (2017), "Eco-friendly Fly Ash Utilization: Potential for Land Application", Critical Reviews in Environmental Science and Technology, Vol. 39, Issue 4, pp. 333-366.

[6] Radhakrishnan, G., Kumar, M.A., and Raju, G.V.R.P. (2014), "Swelling Properties of Expansive Soils Treated with Phosphogypsum and Fly ash", American Journal of Engineering Research. Vol. 3, Issue 4, pp. 245-250.

[7] Raut, J.M., Bajad, S.P., and Khadeshwar, S.P. (2014), "Stabilization of Expansive Soils Using Fly ash and Phosphogypsum", International Journal of Innovative Research in Science, Engineering and Technology. Vol. 3, Issue 7.

[8] [8] RohinKaushik (2014): Have done the research on 'Innovation technique of improving the CBR value of soil using Hair fiber'

[9] Choudhry S, Pandey B (2012) 'Mechanical behavior of polypropylene and human hair Fibers and polypropylene reinforced polymeric composites'. Int J Mech Ind Eng (IJMIE), 2(1):121.

[10] [Senol, A., Etminan. E., and Olgun, C. (2012), "Stabilization of Clayey Soils Using Fly Ash and human hair fiber", GeoCongress, pp. 3929-3938.

[11] Abd el Megeed Kabasy Mohamed, (2012), "Improvement of Swelling Clay Properties Using Hair Fibers", Journal of Engineering Sciences, Vol.40, Issue 5, pp.1337-1349

[12] Bose, B. (2012), "Geo-engineering Properties of Expansive Soil Stabilized with Fly Ash", Electronic Journal of Geotechnical Engineering, Vol. 17, pp. 13391353.

[13] Phanikumar, B.R. (2009), "Effect of Phosphogypsum and Fly Ash on Swell, Consolidation and Shear Strength Characteristics of Expansive Clay: A comparative study", Journal of Geomechanics and Geoengineering: An international journal, Vol. 4, Issue 2, pp. 175-181.

[14] Akhtar JN, Ahmad S (2009) 'The effect of randomly oriented hair fiber on mechanical properties of fly ash based on stabilization of expansive soil'. Asian J Civil Eng, $10(2),: 221-228$

[15] Xing, C., and Ji-ru, Z. (2002), "Stabilization of Expansive Soil by Phosphogypsum and Fly Ash", Journal of Wahan University of Technology - Mater. Sci. Ed., Vol. 14, Issue 4, pp. 73-77. 